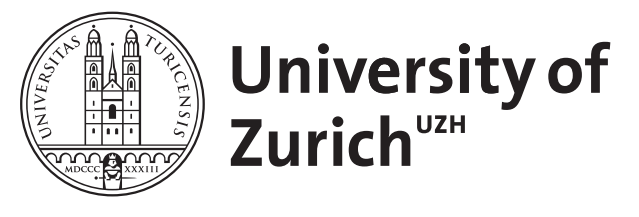

\title{
Open issues in happiness research
}

Frey, Bruno S ; Gallus, Jana ; Steiner, Lasse

\begin{abstract}
Happiness research is one of the most vivid and fruitful parts of modern economics. The focus is on empirical findings. In contrast, theoretical work has been rather neglected. The paper deals with three areas needing more analytical work: the choice or imposition of comparison or reference groups; and the extent, speed and symmetry of adaptation to positive and negative shocks on happiness. In both areas, theoretical propositions are derived which can in the future be empirically tested. The third area relates to the political economy of happiness. Many governments intend to take the happiness index as a criterion of how successful their policies are. As a consequence, survey respondents get an incentive to misrepresent their happiness level, and governments to manipulate the aggregate happiness indicator in their favor. A country's constitution must induce governments to carefully observe human rights, democracy, the decentralization of political decision making, and market institutions and provide people with the possibility to acquire a good education and find a suitable job.
\end{abstract}

DOI: https://doi.org/10.1007/s12232-014-0203-y

Posted at the Zurich Open Repository and Archive, University of Zurich

ZORA URL: https://doi.org/10.5167/uzh-171978

Journal Article

Published Version

Originally published at:

Frey, Bruno S; Gallus, Jana; Steiner, Lasse (2014). Open issues in happiness research. International Review of Economics, 61(2):115-125.

DOI: https://doi.org/10.1007/s12232-014-0203-y 


\title{
Open issues in happiness research
}

\author{
Bruno S. Frey • Jana Gallus $・$ Lasse Steiner
}

Received: 26 August 2013/Accepted: 28 March 2014/Published online: 12 April 2014

(C) Springer-Verlag Berlin Heidelberg 2014

\begin{abstract}
Happiness research is one of the most vivid and fruitful parts of modern economics. The focus is on empirical findings. In contrast, theoretical work has been rather neglected. The paper deals with three areas needing more analytical work: the choice or imposition of comparison or reference groups; and the extent, speed and symmetry of adaptation to positive and negative shocks on happiness. In both areas, theoretical propositions are derived which can in the future be empirically tested. The third area relates to the political economy of happiness. Many governments intend to take the happiness index as a criterion of how successful their policies are. As a consequence, survey respondents get an incentive to misrepresent their happiness level, and governments to manipulate the aggregate happiness indicator in their favor. A country's constitution must induce governments to carefully observe human rights, democracy, the decentralization of political decision making, and market institutions and provide people with the possibility to acquire a good education and find a suitable job.
\end{abstract}

Keywords Happiness - Life satisfaction - Reference group · Adaptation · Policy

JEL Classification A13 - D64

\footnotetext{
B. S. Frey $(\bowtie)$

Zeppelin University, Friedrichshafen, Germany

e-mail: bruno.frey@econ.uzh.ch

B. S. Frey

Center for Research in Economics, Management and the Arts (CREMA), Zurich, Switzerland

J. Gallus · L. Steiner

Department of Economics, University of Zurich, Zurich, Switzerland
} 


\section{Great achievements}

Economic happiness research has been a considerable success. It has become one of the most challenging and visible parts of economic science, opening new and unexpected insights both for theory and policy. Over the last years, many issues of the measurement of subjective well-being have been clarified, and we now know the major determinants of happiness: ${ }^{1}$ genetic, socio-demographic, economic, social and political factors. Their influence has been discussed in several survey papers, such as Frey and Stutzer (2002, 2005a), Dolan et al. (2008), Stutzer and Frey (2010), Frey and Steiner (2012) and most recently Becchetti and Pelloni (2013); the results will not be repeated here.

Various applications of happiness research have opened new avenues for research. It suffices to mention the social evaluation of external events (such as terrorist incidents, see Frey et al. 2009) or of smoking bans on both smokers and nonsmokers (Odermatt and Stutzer 2013). Happiness research allows scholars to take into account aspects such as weakness of will. This weakness cannot be analyzed by standard neoclassical economics, which assumes that individuals always and everywhere behave in a way maximizing their utility. This assumption excludes behavior where individuals fail to act in their best interest, even though for example weakness of will plays a large role in everyday life. It is therefore important to know how damaging it actually is and what can be done about it. A negative relationship between overconsumption and life satisfaction exists, for example for alcohol consumption (Veenhoven 2003), obesity (Stutzer 2009). Benesch et al. (2010) show that for many people, it is tempting to view TV rather than to pursue more engaging activities, because of its immediate benefits at negligible immediate marginal costs. As a consequence, individuals with incomplete control over, and foresight into, their own behavior watch more TV than they consider optimal for themselves and their wellbeing is lower than what could be achieved.

Great advances have also been made concerning causality, e.g., that higher income raises happiness, but happier persons are also better able to raise their income (De Neve and Oswald 2012). The same holds for other determinants of happiness, in particular unemployment and health. The major technique for identifying causality is to consider exogenous changes in the determinants of happiness, for instance winning money at a lottery, which can be considered an unpredicted event. The result shows that a gain in income indeed raises happiness (Gardner and Oswald 2007). Another technique is to consider persons living under similar conditions, such as nuns. Based on this, the effect of happiness on health has been studied. Before young women enter the religious order, their self-declared happiness levels differ. Their subsequent monastic lives are quite similar; they are subject to essentially the same influences. It turns out that those nuns who have been happier before entering the monastery live considerably longer (Danner et al. 2001). This supports the idea that happiness raises health and longevity.

\footnotetext{
${ }^{1}$ Following the literature, the word "happiness" is used for convenience to denote the more scientific term "subjective well-being". This paper deals more narrowly with "life satisfaction" derived from the answers to the survey question: "Taken overall, how satisfied are you with the life you lead". In the case of employment relationships, happiness is identified with job satisfaction.
} 
Past research has been concentrated on empirical findings based on the exploitation of large databases. In the extreme, researchers were satisfied to find any determinant of happiness, as long as it was statistically significant. McCloskey and Ziliak (1996) and Ziliak and McCloskey (2008) have castigated such an approach for years. It may be argued that it is always possible to find some estimated coefficient that surpasses the conventional barriers (mostly 95 and $99 \%$ ) to be considered "statistically significant." But this significance is unrelated to contentand, of course, what should count is a relationship representing substantive issues. The neglect of theoretical work starkly contrasts with the very large number of empirical estimations. It may be due to the considerable amount of potential influences, which makes it difficult if not impossible to construct a formal integrating the crucial aspects.

This paper discusses three areas in which more thorough and more novel theoretical work is needed: comparisons, adaptation and happiness policy. Section 2 deals with the comparison or reference groups which people choose to take or which are imposed on them. Section 3 discusses the extent, speed and symmetry of adaptation to positive and negative shocks on happiness. In both sections, several theoretically derived propositions are made which can be empirically tested in the future. Section 4 considers the political economy of happiness taking account of reactivity. The latter occurs when governments take the happiness index as a criterion of how successfully they act. The last concludes.

\section{Comparison to reference groups}

One of the major insights of happiness research is that individuals have a strong tendency to compare their own situation to that of other people. Happiness research demonstrates that absolute income has strongly decreasing marginal happiness and pronounces the importance of relative income.

\subsection{Empirical results}

When considering personal reference groups, happiness research commonly relates the level of income (or wealth) of an individual to average income in the respective society (on this and the following, Becchetti and Pelloni (2013) provide extensive references to the literature). Changes in relative income have much larger effects on happiness than changes in absolute income. This is a rather crude procedure because a person generally knows only a limited number of other persons. The information provided by the media certainly extends the reference group to a larger set of people, but that set still remains sketchy and might not have much of an impact on people's reference groups. Thus, persons of low income do not normally compare their situation to that of the extremely rich, who live in other parts of the city or region and to whom they never connect. A more sophisticated approach explicitly considers the social environment in which persons live, in particular their friends and colleagues. Men, for example, compare themselves less often to family members than do women, and the self-employed are in general less likely to draw 
such social comparisons (Clark and Senik 2010). It has been shown that individuals observe the consumption pattern of others, even without personally knowing these people (Winkelmann 2012).

The effects of both absolute and relative income on happiness are small when compared to the effects of several non-pecuniary factors. Comparisons are not only made with respect to income but also made with respect to other determinants of happiness, such as unemployment. While losing one's job strongly reduces happiness, the loss is less marked when other persons in the region are also out of work. The individual unemployment effect is even neutralized in areas with a very high employment deprivation (around $24 \%$, see Clark 2003). For those working, having an unemployed partner is detrimental to happiness, but for the unemployed it is beneficial.

Further, there seems to be substantial heterogeneity in the groups to which individuals compare. This diversity seems to be partly endogenous, relating to the type of regular social interactions that individuals experience.

\subsection{Propositions}

The empirical results reached so far do not allow us to draw firm conclusions about how individuals compare themselves to other persons. Firstly, it is unclear what the relevant reference group is in a particular case. Secondly, the reference group is not static but adjusts to various influences. It is, for instance, well known that when individuals' income rises, they start to compare themselves to persons who also dispose of greater income.

Two possibilities may be distinguished:

(a) Individuals can be assumed to be able to choose their reference groups. Utility maximizers may be taken to consider countervailing influences. On the one hand, they obviously feel happier if they compare themselves downwards, for instance to persons with lower income. On the other hand, they may be aware that their "animal spirits" are strengthened if they compare themselves to persons with higher income. Such a comparison induces them to exert more effort in order to raise their future income and happiness. Persons focusing more on the present put more weight on the first, persons with lower discount rates on the second, consideration. This relationship is open to empirical testing.

Proposition 1 The more far-sighted individuals are the more they compare themselves with persons of higher income, and the less happy they are (keeping all other influences on happiness constant).

This proposition can be tested by first determining individuals' discount rates of the future, and then econometrically estimating a happiness function with the discount rate as one of the determinants. However, this procedure is not unproblematic because the extent of discounting tends to depend on the happiness level. As it has been found (Abdel-Khalek 2006) that happier people are more forward looking, a suitable instrument for the rate of discount must be used in order to correctly estimate the effect of the choice of the reference group on happiness. 
(b) The reference group may be assumed to be determined by outside factors imposed on individuals. For instance, persons growing up in a very rich household find it difficult, or impossible, not to compare their present situation with that in their youth. However, it may be feasible to indirectly influence one's reference group. This may be achieved by taking a more basic decision about the type of life one wants to pursue. Individuals deciding to study finance and then work in a bank generally must be aware that the point of reference is monetary income. Once that step is taken, the reference group is composed of persons with higher, and often much higher, income. In contrast, persons choosing to work in the charitable sector expose themselves to vastly different influences. They mostly come in contact with persons of low income, which influences the set of persons whom they compare themselves with. The same occurs if people choose to work in the public sector, in which salaries tend to be lower than for similar work performed in the private sector. These considerations again lead to propositions amenable to empirical tests.

Proposition 2 The richer individuals' parents are the more they tend to compare themselves with higher income persons, and the less happy they are (ceteris paribus).

Proposition 3 Individuals working in the financial sector tend to compare themselves with persons of higher income than do individuals working in the charitable or in the public sectors. The former therefore tends to be less happy than the latter (ceteris paribus).

While proposition 2 points to a setting where factors are imposed from outside, proposition 3 includes the possibility of selection effects. People working in banks may be more prone to comparing themselves along the income dimension, while people with less regard for monetary aspects are more likely to join the voluntary or public sector.

Many other testable propositions with respect to income comparisons can, of course, be developed. Visibility of differences certainly plays a major role. The more intensively the traditional and social media invite, and even impose, comparisons with others' achievements (e.g., promotion on the job, acquisition of status goods, luxurious vacation destinations), the more elevated is the reference group. This applies not only to persons in the same society, but also across nations and continents. The impact of relative comparisons also changes according to the perception of vertical mobility. In counties with high perceived vertical mobility, the income gap to the reference group has less negative effects (see e.g., Senik 2005).

Institutional factors impact the reference group people compare themselves with. A case in point is the publication of employees' salaries, which affects the reference levels obtaining. This effect has recently (Card et al. 2012) been tested using a randomized variation in access to information on the salaries of co-workers. The study shows that employees are indeed interested in knowing the salary of other employees, especially of those in the same department. This information has a strong effect on how relative pay affects job satisfaction. The results of the study suggest that information on other employees' salaries reduces job satisfaction 
among employees with salaries below the median of their department and occupational group. In contrast, job satisfaction of individuals with salaries above the median is unaffected.

\section{Hedonic adaptation}

When the determinants of happiness change, individuals adjust their evaluations of happiness. This adaptation can vary in three regards: (1) the extent of adjustment to the previous happiness level; (2) the speed of adjustment; and (3) the symmetry, i.e., whether an adjustment following a beneficial change takes the same form as an adjustment to an unfortunate event. The last aspect is not further considered in this paper; it would deserve to be analyzed in its own right.

\subsection{Empirical results}

There are a great number of studies showing that individuals adjust their happiness level when they are subject to exogenous shocks (for literature references see again Becchetti and Pelloni 2013). Well known is the downward adjustment occurring after winning a substantial amount of money at a lottery and the accompanying increase in happiness. The "Easterlin Paradox" claims that rising real per capita income does not raise happiness on the country level, but this result is controversial. Several studies (e.g., Deaton 2008; Stevenson and Wolfers 2008, 2013) reject this paradox, at least in its strict sense. Nevertheless, most scholars undertaking research on the relationship between income and happiness hold that happiness does not increase at the same rate as income, i.e., that either some extent of adaptation to higher income levels takes place or that comparison with increasingly wealthy persons takes place (Luttmer 2005).

Recent research has shown that individuals also completely adapt to nonmonetary shocks, except for unemployment (Clark et al. 2008). It does not matter if these events are positively related to happiness, such as marriage or birth of a child, or negatively, such as divorce, an accident leading to disability (Oswald and Powdthavee 2008), widowhood or layoff. In general, the patterns of adaptation are remarkably similar by sex. A special case is the effect of getting unemployed. While both men and women suffer a drastic decline in their happiness, women recover after some time while men do not. Related to the development of happiness over time is a second phenomenon, namely anticipation. Anticipation effects are strongest for events that are expected, as are often a divorce or a marriage. However, the strongest impact on life satisfaction often appears at the time when the events in question occur.

\subsection{Propositions}

The many empirical results concerning the adaptation of happiness to shocks are rarely based on theoretical considerations but are the result of exploiting and interpreting given data such as the German Socio-Economic Panel. 
There seems to be a difference between psychologists and economists engaging in this research. Many psychologists assume that there is a homeostatic force in human beings re-establishing a "set point of happiness," which differs between persons. Efforts to raise happiness by changing its determinants only have a transitory effect. For many economists, the idea of a set point of individual happiness is rather far off. This may be due to the influence of standard economics where according to the received utility function, an increase in income produces higher utility.

The extent and form of adaptation of happiness can be assumed to depend on various factors:

(a) Individuals are more strongly induced to adapt their happiness levels when they perceive no alternative available to them. Most of them realize that it is useless to mourn about an unfortunate event that cannot be altered. Indeed, to keep mourning about an unachievable state can be considered a pathological trait (Stroebe et al. 2000).

Proposition 4 The fewer alternatives the individuals affected perceive, the harder they are hit by a negative shock and the stronger and the faster they adapt their happiness to the previous level.

(b) Individuals may be subject to pressures to adapt which differ between identifiable conditions. For instance, when the competitive struggle for survival is strong - as it has been in most periods of mankind-individuals cannot afford not to mentally adapt to new conditions. The more they internalize the prevailing conditions in which they live, the better are they able to survive. In contrast, in a modern social welfare state, there is less pressure to adjust to new conditions.

Proposition 5 When hit by a negative shock, individuals adapt more slowly, and to a lesser extent, in a social welfare state than under conditions of intense competitive survival.

(c) Persons with many social contacts, i.e., having an intact family, friends and acquaintances, are helped and supported after a negative shock to adapt to new conditions. After a positive shock, the support via social contacts enables them to feel less pressure to adapt. In contrast, isolated persons may find it more difficult to adjust and therewith are likely to suffer a greater loss of happiness when they are hit by negative shocks.

Proposition 6 Individuals with more social contacts adjust less quickly to beneficial, and more quickly to unfortunate events than do more isolated persons.

There may be many other interesting theoretical propositions with respect to the extent and speed of adaptation as well as to possible asymmetries in reactions to positive and negative shocks. The same holds for the preceding theoretical discussion on comparisons. A third field that deserves more attention by academics is the political economy of happiness research. 


\section{Policy consequences}

Happiness research is faced by fundamental problems of reactivity, rarely taken into account in existing research (Frey and Stutzer 2009, 2012; Frey and Gallus 2012). As has been well established, surveys on life satisfaction have been a useful and good proxy to the theoretical concept of utility (e.g., Kahneman 2003). Changes in life satisfaction reflect well how people "really" feel; they also closely correlate with objective observations such as smiling. The situation has, however, changed since politicians such as (former) French president Sarkozy and British Prime Minister Cameron have jumped on the bandwagon of happiness. They proclaimed their intent to use the aggregate happiness index as a criterion supposedly reflecting their performance. What had worked before-namely, the dependability of the surveys on life satisfaction-no longer works because of two kinds of reactivity (Frey and Gallus 2013a):

(a) When the individuals surveyed about their happiness know that politicians use the results for their own political purposes they are induced to give strategic answers. For example, persons with a left-wing ideology may be reluctant to state that they are particularly happy if the government in power is of a right-wing orientation. Being aware that stating that they are happy benefits the politicians they dislike, they tend to state a lower happiness level than they would otherwise report. Conversely, if a left-wing government is in power, they tend to distort their happiness level in the upward direction.

(b) Governments have a strong incentive to manipulate the overall happiness level as they know that the voters now judge them on this criterion. This type of reactivity has taken place since the advent of aggregate economic indicators. Changes in national income, unemployment, inflation, fiscal deficit and public debt are politically important and have therefore been manipulated by governments. The same occurs when happiness is taken to be a criterion of government performance. However, the macro-economic indicators are (mostly) based on (more or less) objective data such as turnover and value added. In contrast, aggregate happiness indicators are derived from intently subjective data and are therefore easier to manipulate.

It may be argued that the insights gained by happiness research should directly inform policy makers and be considered a criterion of success. Hence, it is a worthwhile endeavor to consider how the risks attached to one single national happiness index may be mitigated. One possibility to overcome the distortions induced by reactivity is to prevent the government from manipulating the aggregate happiness index. A country's Statistical Office could be assigned the task to construct the index. However, in most countries, even those with a long democratic tradition, the Statistical Office is at best formally independent, and often subject to outright influence by the politicians in power (similar to Central Banks). Another possibility is to impose a strict protocol on how to construct the aggregate happiness index. This would be similar to the construction of national income indices. However, this requirement has not prevented governments to include (in order to magnify economic success) or to exclude (in order to get higher subsidies from 
other countries) parts of or the entire shadow economy. Not even a strict protocol overcomes the government's strong incentives to manipulate the aggregate happiness index. Another problem for happiness policies arises when individuals mispredict the future utility of goods consumed and activities undertaken (Frey and Stutzer 2005b). Goods and activities characterized by stronger intrinsic aspects (such as spending time with family and friends and pursuing hobbies) are undervalued compared to those characterized by stronger extrinsic aspects (such as income). Whether the effects of mispredicting utility are mitigated or are even accentuated in the political process is not clear ex-ante and depends on the political conditions.

The issue of reactivity has to be addressed at a more fundamental, social-rather than administrative-level (Frey and Stutzer 2009; Frey and Gallus 2013b). A country's constitution must induce and force governments to obey human rights, democracy, the decentralization of political decision making and free markets. On a somewhat lower constitutional level, the constitution must give citizens the possibility to acquire the best possible education and to find a job matching their abilities and preferences. As a result, the citizens will be able to enjoy high happiness. The government's task is to set the conditions such that citizens can attain happiness rather than directly seeking to make citizens happy. History shows that most, if not all, governments which claimed, and perhaps even endeavored, to make their citizens happy ended up as a happiness dictatorship. The French Revolutionaries whose effort led to "la terreur" (the Reign of Terror, from 1793 to 1794) provide a case in point.

\section{Concluding remarks}

Happiness research is one of the most interesting parts of modern economics, and more broadly of the social sciences. The research has been concentrated on empirical findings based on the exploitation of large databases. In the extreme, researchers have been satisfied when they were able to find statistically significant determinants of happiness. In contrast, theoretical work has been somewhat neglected.

Three areas are discussed in which more thorough and more novel analytical work is needed. The first area refers to the comparison or reference groups which people choose to take or which are imposed on them. The second area concerns the extent, speed and symmetry of adaptation to positive and negative shocks on happiness. In both areas several propositions are made which can in the future be empirically tested.

The third area relates to the political economy of happiness taking account of reactivity. The latter occurs when governments take the happiness index as a criterion of how successful their policies are. As a consequence, the people surveyed get an incentive to misrepresent their happiness level, and governments get an incentive to manipulate the aggregate happiness level in their favor. The political economy aspect is particularly challenging as it is a result of happiness research. It is exactly its success that induces politicians to employ it as a favorable criterion of 
their own performance. Administrative solutions to overcoming distorted happiness indicators are unlikely to work. Rather, a country's constitution must induce governments to carefully observe human rights, democracy, the decentralization of political decision making, and the freedom of markets. On a somewhat lower constitutional level the constitution must give citizens the possibility to acquire a good education, and to find a suitable job.

\section{References}

Abdel-Khalek AM (2006) Measuring happiness with a single-item scale. Soc Behav Personal 34:139-150 Becchetti L, Pelloni A (2013) What are we learning from the life satisfaction literature? Int Rev Econ 60:113-155

Benesch C, Frey BS, Stutzer A (2010) TV channels, self-control and happiness. BE J Econ Anal Policy 10:1-33

Card D, Mas A, Moretti E, Saez E (2012) Inequality at work: the effect of peer salaries on job satisfaction. AER 102:2981-3003

Clark AE (2003) Unemployment as a social norm: psychological evidence from panel data. J Labor Econ 21:323-351

Clark AE, Senik C (2010) Who compares to whom? The anatomy of income comparisons in Europe. Econ J 120:573-594

Clark AE, Diener E, Georgellis Y, Lucas RE (2008) Lags and leads in life satisfaction: a test of the baseline hypothesis. Econ J 118:222-243

Danner DD, Snowdon DA, Friesen WV (2001) Positive emotions in early life and longevity: findings from the nun study. J Personal Soc Psychol 80:804-813

De Neve JE, Oswald A (2012) Estimating the influence of life satisfaction and positive affect on later income using sibling fixed effects. PNAS 109:19953-19958

Deaton A (2008) Income, health and wellbeing around the world: evidence from the Gallup World Poll. J Econ Perspect 22:53

Dolan P, Peasgood T, White M (2008) Do we really know what makes us happy? A review of the economic literature on the factors associated with subjective well-being. J Econ Psychol 29:94-122

Frey BS, Gallus J (2012) Happiness policy and economic development. Int J Happiness Dev 1:102-111

Frey BS, Gallus J (2013a) Subjective well-being and policy. Topoi 32(2):207-212

Frey BS, Gallus J (2013b) Political economy of happiness. Appl Econ 45:4205-4211

Frey BS, Steiner L (2012) Glücksforschung: Eine empirische Analyse. AStA 6:9-25

Frey BS, Stutzer A (2002) What can economists learn from happiness research? J Econ Lit 40:402-435

Frey BS, Stutzer A (2005a) Happiness research: state and prospects. Rev Soc Econ 63:207-228

Frey BS, Stutzer A (2005b) Does the political process mitigate or accentuate individual biases due to mispredicting future utility? In: McCaffey E, Slemrod J (eds) Behavioral public finance: toward a new agenda. Russell Sage Foundation, New York, pp 1-44

Frey BS, Stutzer A (2009) Should national happiness be maximized? In: Dutt AK, Radcliff B (eds) Happiness, economics and politics: towards a multi-disciplinary approach. Edward Elgar, Northampton, pp 301-323

Frey BS, Stutzer A (2012) The use of happiness research for public policy. Soc Choice Welf 38:659-674

Frey BS, Luechinger S, Stutzer A (2009) The life satisfaction approach to valuing public goods: the case of terrorism. Public Choice 138:317-345

Gardner J, Oswald AJ (2007) Money and mental wellbeing: a longitudinal study of medium-sized lottery wins. J Health Econ 26:49-60

Kahneman D (2003) Objective happiness. In: Kahneman D, Diener E, Schwarz N (eds) Well-being: the foundations of hedonic psychology. Russell Sage Foundation, New York, pp 3-25

Luttmer EFP (2005) Neighbors as negatives: relative earnings and well-being. QJE 120:963-1002

McCloskey DN, Ziliak ST (1996) The standard error of regressions. J Econ Lit 34:97-114

Odermatt R, Stutzer A (2013) Smoking bans, cigarette prices and life satisfaction. IZA Discussion Paper 7177 
Oswald AJ, Powdthavee N (2008) Does happiness adapt? A longitudinal study of disability with implications for economists and judges. J Public Econ 92:1061-1077

Senik C (2005) Income distribution and well-being: what can we learn from subjective data? J Econ Surv 19:43-63

Stevenson B, Wolfers J (2008) Economic growth and subjective well-being: Reassessing the Easterlin paradox. Brookings Pap Econ Act 39:1-102

Stevenson B, Wolfers J (2013) Subjective well-being and income: Is there any evidence of satiation? NBER Working Paper 18992

Stroebe M, van Son M, Stroebe W, Kleber R, Schut H, van den Bout J (2000) On the classification and diagnosis of pathological grief. Clin Psychol Rev 20:57-75

Stutzer A (2009) Happiness when temptation overwhelms willpower. In: Dutt AK, Radcliff B (eds) Happiness, economics, and politics: toward a multi-disciplinary approach. Edward Elgar, Cheltenham, pp 97-126

Stutzer A, Frey BS (2010) Recent advances in the economics of individual subjective well-being. Soc Res 77:679-714

Veenhoven R (2003) Hedonism and happiness. J Happiness Stud 4:437-457

Winkelmann R (2012) Conspicuous consumption and satisfaction. J Econ Psychol 33:183-191

Ziliak ST, McCloskey DN (2008) The cult of statistical significance: how the standard error costs us jobs, justice, and lives. University of Michigan Press, Ann Arbor 